\title{
SLEEP HYGIENE DENGAN GANGGUAN TIDUR REMAJA
}

\author{
Ni Luh Agustini Purnama \\ STIKES Katolik St.Vincentius a Paulo Surabaya, Jln Jambi 12-18 Surabaya \\ e-mail: niluh@stikvinc.ac.id
}

\begin{abstract}
ABSTRAK
Tidur merupakan salah satu kebutuhan dasar manusia yang penting untuk pertumbuhan fisik dan perkembangan intelektual. Masa remaja rentang mengalami gangguan tidur. Gangguan tidur yang dialami remaja merupakan dampak dari perilaku sleep hygiene yang buruk. Sleep hygiene ini sangat penting untuk memprediksi kualitas dan kuantitas tidur pada remaja. Penelitian ini betujuan mengidentifikasi hubungan sleep hygiene dengan gangguan tidur remaja. Desain penelitian observasi dengan rancangan cross sectional. Subjek penelitian 80 siswa di SMA Katolik Karitas 3 Surabaya memenuhi kriteria inklusi. Perilaku sleep hygiene dinilai menggunakan kuesioner The Adolescent Sleep Hygiene Scale. Penilaian gangguan tidur pada remaja menggunkan kuesioner SDSC (Sleep Disturbances Scale for Children). Perilaku sleep hygiene dalam aspek koqnitif signifikan berhubungan negative dengan gangguan tidur $(\rho=-0,35 \mathrm{p}=0,001)$. Hal ini menunjukkan bahwa semakin baik perilaku sleep hygene dalam aspek kognitif maka semakin menurun skor gangguan tidur. Perilaku sleep hygiene dalam aspek stabilitas tidur berhubungan negatif dengan gangguan tidur $(\rho=-0,358 p=0,001)$, hal ini berarti semakin baik perilaku hygiene dalam aspek stabilitas tidur maka semakin menurun skor gangguan tidur. Program pendidikan kesehatan di sekolah tentang sleep hygiene efektif perlu dilakukan meningkatkan kualitas tidur masa remaja.
\end{abstract}

Kata kunci: gangguan tidur, sleep hygiene, remaja

\begin{abstract}
Sleep is one of the basic human needs that is important for physical growth and intellectual development. Adolescence is prone to sleep disorders. Sleep disorders experienced by adolescents are the result of poor sleep hygiene behavior. Sleep hygiene is very important to predict the quality and quantity of sleep in adolescents. This study aims to identify sleep hygiene relationships with adolescent sleep disorders. Design of observational research with cross sectional design. The research subjects 80 students at the Karitas 3 Surabaya High School Catholic fulfilled the inclusion criteria. Sleep hygiene behavior was assessed using the adolescent sleep hygiene scale questionnaire. Assessment of sleep disorders in adolescents used the SDSC (Sleep Disturbances Scale for Children) questionnaire. Sleep hygine behavior for positive aspects was significantly negatively related to sleep disturbance $(\rho=-0.35 p=0.001)$. This shows that the better the sleep hygene behavior in the cognitive aspect, the lower the sleep disturbance score. Sleep hygiene behavior in aspects of sleep stability is negatively related to sleep disturbances $(\rho=-0.358 p=$ 0.001), this means that the better hygiene behavior in aspects of sleep stability, the lower sleep disturbance scores. School intervention programs need to be conducted effective sleep hygiene needs to be done to improve the quality of sleep in adolescence.
\end{abstract}

Keywords: sleep disorders, sleep hygiene, adolescence 


\section{PENDAHULUAN}

Tidur merupakan bagian penting dalam pertumbuhan fisik dan perkembangan intelektual remaja (Kieckhefer, Ward, Tsai, \& Lentz, 2008). Tidur akan memberikan ketenangan dan memulihkan energi, memulihkan fungsi otak dan tubuh, juga mempertahankan kelangsungan hidup (Kozier, 2011). Remaja memerlukan 8 sampai 10 jam waktu tidur setiap malam untuk mencegah keletihan yang tidak perlu dan kerentanan terhadap infeksi (Kozier, 2011; The National Sleep Foundation (NSF), 2015)

Masa remaja rentang mengalami gangguan tidur (Haryono et al., 2009). Gangguan yang berhubungan dengan tidur dikarenakan masalah medis, gaya hidup, faktor lingkungan menyebabkan tidur terganggu, dan kualitas tidur yang buruk, kondisi ini dinamakan dengan gangguan tidur (National Neuroscience Institute, 2014). Dalam beberapa tahun terakhir, perubahan pola tidur banyak dialami oleh remaja yang menyebabkan penurunan kualitas dan kuantitas tidur. Perubahan pola tidur itu antara lain penurunan durasi tidur, keterlambatan dalam waktu tidur, perbedaan pola tidur antara hari sekolah dengan akhir pekan, dan perubahan kualitas tidur (Lebourgeois, Giannotti, Cortesi, Wolfson, \& Harsh, 2004) Menurut penelitian Haryono et al (2009), jenis gangguan tidur yang dialami remaja meliputi gangguan memulai dan mempertahankan tidur, gangguan pernapasan saat tidur, gangguan kesadaran saat tidur, gangguan transisi tidur bangun, gangguan somnolen berlebihan, dan hiperhidrosis saat tidur.

Pada masa remaja pertengahan (middle adolescent), banyak terjadi perubahan perilaku yang signifikan (Gunarsa, 2008). Aktifitas yang dilakukan remaja saat di rumah lebih difokuskan di kamar tidur. Remaja pada masa ini juga mengalami emosi yang masih labil, sehingga tidak jarang akan mengganggu tidurnya (Soetjiningsih \& Ranuh, 2014). Gangguan tidur yang dialami remaja merupakan dampak dari perilaku sleep hygiene yang buruk (Lebourgeois et al., 2004). Sleep hygiene merupakan praktik perilaku yang meningkatkan kualitas tidur, durasi tidur yang cukup, dan kesiapsiagaan penuh pada siang hari (Kor \& Mullan, 2011). Sleep hygiene ini sangat penting untuk memprediksi kualitas dan kuantitas tidur pada remaja (Mastin, Bryson, \& Corwyn, 2006)

Remaja yang memiliki sleep hygiene yang buruk dapat mengalami kurang tidur, sehingga mengantuk di siang hari. Remaja yang tidurnya tidak memadai rentan terhadap depresi, kecemasan dan kesehatan fisik yang buruk (Kor \& Mullan, 2011). Kualitas dan kuantitas tidur yang kurang pada remaja dapat mempengaruhi prestasi akademik karena menyebabkan penurunan motivasi untuk berpartisipasi di sekolah, penurunan kewaspadaan dan konsentrasi, remaja menjadi cepat marah, impulsif, serta menunjukkan kesedihan (Ya'kub, Widodo, \& Putri, 2017; Noland, 2009). Dampak lain dari kuantitas tidur yang tidak memadai pada remaja adalah resiko obesitas. Beberapa penelitian mengungkapkan bahwa sejumlah perubahan hormonal akibat kuantitas tidur yang tidak memadai dapat menyebabkan peningkatan asupan kalori (Mastin et al, 2006). Dalam setiap jam berkurangnya waktu tidur remaja, kemungkinan terjadi obesitas sebesar 80\% (Mastin et al, 2006).

Di Indonesia prevalensi gangguan tidur pada remaja juga tinggi, remaja usia 12-15 tahun sebanyak 62,9\% mengalami gangguan tidur dengan gangguan transisi bangun-tidur sebagai jenis gangguan yang paling sering ditemui yaitu sebanyak 62,9\%, (Haryono et al, 2009). Dari hasil penelitian Auliyanti, Sekartini, \& Mangunatmadja (2015) di beberapa Sekolah Menengah Pertama di Indonesia prevalensi gangguan tidur didapatkan 39,7 \%, dengan gangguan kesulitan memulai dan mempertahankan tidur sebanyak $70,2 \%$. Melalui survey pendahuluan yang dilakukan bulan November 2017 di SMA Katolik Karitas 3 Surabaya dari 10 orang siswa, 7 siswa mengatakan tidur diatas jam 12 dan 3 siswa mengatakan tidur sebelum jam 12 malam, mereka semua mengatakan merasa kurang dengan waktu tidurnya dan 9 siswa mengatakan sulit untuk memulai tidur dan juga mereka sering terbangun, sehingga mereka merasa mengantuk dan tidak dapat berkonsentrasi saat pelajaran berlangsung.

Penelitian tentang gangguan tidur remaja sudah banyak dilakukan namun gangguan tidur yang dihubungkan dengan perilaku sleep hygine masih terbatas terutama penelitian yang dilakukan di Indonesia. Penelitian ini diharapkan dapat membantu 
tenaga kesehatan khususnya dalam memberikan memberikan konseling tentang perilaku sleep hygiene yang baik dan pendidikan kepada orang tua dan anak tentang pola tidur yang normal. Penelitian ini bertujuan mengidentifisasi hubungan sleep hygiene dengan gangguan tidur remaja

\section{BAHAN DAN METODE}

Penelitian ini adalah penelitian observasi (non eksperimental) dengan rancangan penelitian cross sectional. Penelitian ini melihat keterkaitan hubungan antara variabel yaitu perilaku sleep hygiene dengan gangguan tidur remaja. Pengumpulan data dilaksanakan pada bulan April 2018 di SMA Katolik Karitas 3 Surabaya Subyek dalam penelitian ini adalah Siswa SMA Katolik Karitas 3 Surabaya yang memenuhi kriteria inklusi: berusia 14-17 tahun dan bersedia menjadi responden. Besar sampel pada penelitian ini adalah 80 responden yang diambil dengan teknik stratified random sampling. Setelah menjelaskan maksud dan tujuan penelitian dan mendapat persetujuan orang tua, orang tua dan siswa diminta untuk mengisi kuesioner.

Perilaku sleep hygiene dinilai menggunakan kuisioner Adolescent Sleep Hygiene Scale (ASHS) untuk mengukur tingkat kebiasaan yang dilakukan sebelum tidur (sleep hygiene). Kuisioner ini dikembangakan oleh Lebourgeois et al. (2004) kemudian disempurkana dalam penelitian selanjutnya oleh Storfer-Isser, Lebourgeois, Harsh, Tompsett, \& Redline (2013). Kuesioner ini tersedia dalam bahasa Inggris kemudian peneliti dibantu ahli bahasa untuk menerjemahkan ke bahasa Indonesia. Adolescent Sleep Hygiene Scale (ASHS) merupakan instumen yang terdiri dari 28 item pertanyaan dan 9 sub skala. Pilihan jawaban menggunakan skala likert, yang terdiri dari 6 pilihan jawaban yaitu Selalu=1, Sering=2, Agak sering=3, Kadang-kadang=4, Jarang=5, Tidak pernah=6. Interpretasi skor dari kuesioner dengan menghitung rata-rata dari setiap indicator, semakin tinggi skore menunjukkan sleep hygiene yang semakin baik. Pada uji validitas kuesioner dengan product moment test, dari 28 item pertanyaan menunjukkan nilai yang valid dengan $r=0,733$ 0,888. Uji reliabilitas kuisioner ASHS

menunjukkan nilai Alpha koefisien Cronbach ( $\alpha$ ) 0,9 yang berarti reliabel

Gangguan tidur remaja dinilai menggunakan Kuesioner SDSC (Sleep Disturbances Scale for Children). Instrumen penelitian SDSC ini di publikasikan oleh Bruni (1996) dan sudah tersedia dalam bahasa Inggris, di Indonesia kuesioner ini digunakan oleh Natalita et al. (2011) untuk menilai gangguan tidur pada pelajar berusia 12-15 tahun, SDSC dapat digunakan sebagai alat skrining gangguan tidur pada remaja dengan nilai sensitivitas $71,4 \%$ dan spesifisitas $54,5 \%$. Kuesioner ini sudah di uji coba pada remaja di SMAN 11 Surabaya pada tanggal 4 Januari 2018, menggunakan pearson product momentdan valid $\mathrm{r}=0,310-0,639$, uji reliabilitas menggunakan Alpha Cronbach $(\alpha=$ 0,702).

Instrumen ini terdiri dari 26 item pertanyaan, dinilai dalam 5 poin skala intensitas atau frekuensi. Penilaian SDSC ini dilakukan dengan menggunakan angka mulai dari 1 sampai dengan 5. Angka 1 untuk tidak pernah, 2 untuk jarang (1 atau 2 kali per bulan atau kurang), 3 untuk kadang-kadang (1 atau 2 kali seminggu), 4 untuk sering ( 3 sampai 5 kali seminggu) dan 5 untuk selalu (setiap hari) (Natalita et al., 2011). Skor < 45 menunjukkan tidak ada gangguan tidur, skor > 45 menunjukkan ada gangguan tidur. Analisis bivariat dilakukan untuk mengidentifikasi hubungan antara perilaku sleep hygiene dengan gangguan tidur. Pengolahan dan analisis data menggunakan program computer pengolahan data statistik dengan tingkat kemaknaan $\mathrm{p}<$ 0,05 dan interval kepercayaan $95 \%$.

HASIL

Tabel 1 Karateristik Responden

\begin{tabular}{lcc}
\hline \multicolumn{1}{c}{ Variabel } & $\begin{array}{c}\text { Frekuen } \\
\text { si (n) }\end{array}$ & $\begin{array}{c}\text { Prese } \\
\text { ntase } \\
(\%)\end{array}$ \\
\hline $\begin{array}{l}\text { Pendidikan terakhir ibu } \\
\begin{array}{l}\text { Dasar (SD s/d } \\
\text { SMP/Sederajat) }\end{array}\end{array}$ & 8 & 10 \\
$\begin{array}{l}\text { Menengah (SMA) } \\
\text { Tinggi (Perguruan Tinggi) } \\
\text { Pendidikan terakhir ayah }\end{array}$ & 44 & 55 \\
$\begin{array}{l}\text { Dasar (SMP/Sederajat) } \\
\text { Menengah (SMA/ }\end{array}$ & 5 & 6 \\
$\begin{array}{l}\text { sederajat) } \\
\text { Tinggi (Perguruan Tinggi) } \\
\text { Pekerjaan Ayah }\end{array}$ & 35 & 56 \\
\end{tabular}




\begin{tabular}{lcc}
\hline \multicolumn{1}{c}{ Variabel } & $\begin{array}{c}\text { Frekuen } \\
\text { si (n) }\end{array}$ & $\begin{array}{c}\text { Prese } \\
\text { ntase } \\
(\%)\end{array}$ \\
\hline $\begin{array}{l}\text { Bekerja } \\
\text { Tidak bekerja }\end{array}$ & 74 & 92,5 \\
Pekerjaan Ibu & 6 & 7,5 \\
$\begin{array}{l}\text { Bekerja } \\
\text { Tidak bekerja }\end{array}$ & 46 & 57,5 \\
Pendapatan Keluarga & 34 & 42,5 \\
< Rp.3.500.000 & & \\
>Rp.3.500.000 & 27 & 34 \\
\hline
\end{tabular}

Berdasarkan hasil dari 80 responden yaitu, bila dilihat dari pendidikan terakhir ibu sebesar $35 \%$ adalah menengah dan dilihat dari pendidikan terakhir ayah sebesar $56 \%$ adalah menengah. Kemudian dilihat dari pekerjaan ayah dan ibu sebesar 92,5\% ayah bekerja dan $57,5 \%$ ibu bekerja, bila dilihat dari pendapatan keluarga yang berpenghasilan >Rp. $3.500 .000,00$ sebesar $66 \%$.

Tabel 2 Perilaku sleep hygiene remaja

\begin{tabular}{lc}
\multicolumn{1}{c}{ Indikator } & Mean $\pm \mathrm{SD}$ \\
\hline Fisiologis & $4,28 \pm 0,67$ \\
Kognitif & $2,81 \pm 0,88$ \\
Emosional & $4,51 \pm 1,09$ \\
Lingkungan tidur & $4,02 \pm 1,08$ \\
Tidur siang & $3,76 \pm 1,77$ \\
Zat & $5,82 \pm 0,53$ \\
Rutinitas tidur & $4,31 \pm 1,52$ \\
Stabilitas tidur & $3,51 \pm 0,67$ \\
Teman tidur & $3,08 \pm 0,81$ \\
\hline 1=Selalu 2=Sering 3=Agak sering \\
4=Kadang-kadang 5=Jarang 6=Tidak \\
pernah
\end{tabular}

Berdasarkan tabel 2, pada masing-masing indikator perilaku sleep hygiene terdapat 6 pilihan jawaban dimana semakin tinggi skor menunjukkan perilaku sleep hygiene yang semakin baik. Perilaku sleep hygiene dalam indikator kognitif pada rentang sering sampai agak sering, dalam hal melakukkan hal-hal yang membuat terjaga selama 1 jam sebelum tidur, (bermain game, menonton televise, membaca), melakukan aktifitas di tempat tidur misalnya , menggunakan tempat tidur untuk hal-hal lain selain tidur (misalnya menelpon, menonton televises, bermaina game, mengerjakan PR. Perilaku yang paling baik dilakukan adalah aspek zat yang itu pada rentang jarang-tidak pernah dalam hal merokok dan minum minuman beralkohol setelah jam 18.00 .

Tabel 3 Kategori Gangguan Tidur yang Dialami Remaja

\begin{tabular}{|c|c|c|}
\hline $\begin{array}{c}\text { Kategori Gangguan } \\
\text { Tidur }\end{array}$ & $\begin{array}{l}\text { Frekuensi } \\
\text { (n) }\end{array}$ & $\begin{array}{c}\text { Presentase } \\
(\%)\end{array}$ \\
\hline $\begin{array}{l}\text { Gangguan Memulai } \\
\text { dan Mempertahankan } \\
\text { Tidur }\end{array}$ & 67 & 84 \\
\hline $\begin{array}{l}\text { Gangguan Transisi } \\
\text { Bangun Tidur }\end{array}$ & 13 & 16 \\
\hline
\end{tabular}

Dari 80 reponden Siswa/Siswi Kelas X dan XI SMA Katolik Karitas 3 Surabaya sebanyak $100 \%$ mengalami gangguan tidur dengan dua kategori jenis gangguan tidur yang paling banyak yaitu gangguan memulai dan mempertahankan tidur serta gangguan transisi bangun tidur. Dari hasil data ini kategori jenis gangguan tidur terbanyak siswa/siswi SMA Katolik Karitas 3 Surabaya adalah gangguan memulai dan mempertahankan tidur sebanyak 84\% (67) responden.

Tabel 4 Hubungan skor perilaku sleep hygiene dengan skor gangguan tidur, N=80 (Spearman Correlation)

\begin{tabular}{lll}
\hline \multirow{2}{*}{$\begin{array}{l}\text { Perilaku sleep } \\
\text { hygiene }\end{array}$} & \multicolumn{2}{c}{ Gangguan tidur } \\
\cline { 2 - 3 } & $\mathrm{p}$ & $\begin{array}{l}\text { Koefisien } \\
\text { korelasi }(\rho)\end{array}$ \\
\hline Fisiologis & 0,460 & $-0,085$ \\
Kognitif & $0,001^{*}$ & $-0,35$ \\
Emosional & 0,068 & $-0,205$ \\
Lingkungan tidur & 0,178 & $-0,152$ \\
Tidur siang & 0,227 & $-0,137$ \\
Zat & 0,241 & $-0,133$ \\
Rutinitas tidur & 0,460 & $-0,084$ \\
Stabilitas tidur & $0,001^{*}$ & $-0,358$ \\
Teman tidur & 0,275 & 0,123 \\
Skor total & $0,002^{*}$ & $-0,349$ \\
\hline Kerang
\end{tabular}

Keterangan: signifikan $\mathrm{p}<0,05$

Perilaku sleep hygine dalam untuk aspek koqnitif signifikan berhubungan negative dengan gangguan tidur $(\rho=-0,35 p=0,001)$. Hal ini menunjukkan bahwa semakin baik perilaku sleep hygene dalam aspek kognitif maka semakin menurun skor gangguan tidur. Perilaku sleep hygiene dalam aspek stabilitas tidur berhubungan negatif dengan gangguan tidur $(\rho=-0,358 \mathrm{p}=0,001)$, hal ini berarti semakin baik perilaku hygiene dalam aspek 
stabilitas tidur maka semakin menurun skor gangguan tidur.

\section{PEMBAHASAN}

Hasil penelitian menunjukkan bahwa perilaku sleep hygiene remaja yang paling rendah dalam indikator kognitif artinya remaja sering melakukkan hal-hal yang membuat terjaga selama 1 jam sebelum tidur (bermain game, menonton televise), melakukan aktifitas di tempat tidur, menggunakan tempat tidur untuk hal-hal lain selain tidur (misalnya menelpon, menonton televisi, bermaina game, mengerjakan PR). Hasil ini sejalan dengan penelitian yang dilakukan Harmoniati, Sekartini, \& Gunardi (2016) bahwa sebagian besar anak melakukan kebiasaan sebelum tidur yang juga memengaruhi kualitas tidur seperti menonton TV atau bermaian elektronik sebelum tidur. Nursalam, Apriani, Has, \& Efendi (2013) juga melaporkan bahwa perilaku sleep hygiene dari aspek kognitif mayoritas remaja Bali adalah melakukan hal-hal di tempat tidur yang membuat remaja terjaga seperti menggunakan ponsel.

Noland et al (2009) dan Malone (2011) mendefinisikan sleep hygiene yang baik salah satunya adalah menghindari aktifitas di tempat tidur selain untuk tidur. Lingkungan merupakan salah satu faktor yang mempengaruhi sleep hygiene. Lingkungan yang disediakan untuk tidur harus bebas dari kebisingan, cahaya, suhu yang berlebihan bahkan teman tidur yang mungkin mendengkur. Gangguan lingkungan tidur lainnya meliputi kegiatan yang dilakukan di tempat tidur seperti, menonton televisi di tempat tidur, menelpon, dan membaca. Remaja sering melakukan sleep hygiene yang buruk. Aktifitas yang dilakukan remaja saat di rumah lebih difokuskan di kamar tidur (Soetjiningsih \& Ranuh, 2014).

Berdasarkan hasil penelitian semua remaja mengalami gangguan tidur, mayoritas mengalami gangguan untuk memulai dan mempertahankan tidur. Gangguan memulai dan mempertahankan tidur merupakan tidur non restoratif dimana remaja merasa saat terbangun dari tidur, masih merasa tidurnya belum cukup. Hasil ini juga sejalan dengan temuan Haryono et al., (2009) bahwa lebih dari $50 \%$ remaja di Jakarta mengalami gangguan memulai dan mempertahankan tidur. Menurut
Soetijiningsih (2013), remaja yang mengalami kesulitan memulai dan mempertahankan tidur memiliki tanda - tanda lama tidur di malam hari kurang dari 7-8 jam, waktu yang dibutuhkan untuk memulai tidur lebih dari 60 menit, kesulitan tidur di malam hari, rasa takut ketika memulai tidur, sering terbangun saat tidur, saat terbangun remaja sulit untuk tidur kembali.

Perilaku sleep hygiene signifikan berhubungan negatif dengan gangguan tidur artinya semakin menurun skor perilaku sleep hygiene maka semakin meningkat skor gangguan tidur remaja. Hasil ini menunjukkan bahwa semakin baik perilaku sleep hygiene remaja maka semakin menurun gangguam tidur yang dialami. Secara khusus perilaku sleep hygiene dalam aspek kognitif dan stabilitas tidur. Hal ini menunjukkan bahwa semakin baik perilaku sleep hygene dalam aspek kognitif maka semakin menurun skor gangguan tidur. Aspek kognitif dalam penelitian ini adalah melakukkan hal-hal yang membuat terjaga selama 1 jam sebelum tidur (bermain game, menonton televisi), melakukan aktifitas di tempat tidur, menggunakan tempat tidur untuk hal-hal lain selain tidur (misalnya menelpon, menonton televisi, bermaina game, mengerjakan PR).

Suen, Tam, \& Hon, (2010) juga menyatakan bahwa perilaku sleep hygiene mahasiswa berhubungan dengan kualitas tidur. Kualitas tidur yang buruk berkaitan dengan sleep hygiene yang kurang seperti menonton televisi dan belajar di tempat tidur. Ketidak adekuatan kualitas dan kuantitas tidur pada remaja disebabkan berbagai hal salah satunya adalah perilaku sleep hygiene. Penggunaan media seperti internet, Hp, bermain game, menonton televisi akan mempengaruhi jumlah total tidur dan mempengaruhi kualitas tidur dan mendorong waktu tidur menjadi tidak teratur (Zimmerman, 2008). Calamaro, Yang, Ratcliffe, \& Chasens (2012) menyebutkan bahwa anak yang menggunakan barang-barang teknologi di kamar tidur menyebabkan periode waktu tidur menjadi lebih singkat. Aktivitas yang bersifat stimulasi baik secara kongnitif, psikologis, maupun emosional dapat meningkatkan kejadian gangguan tidur. Kegiatan tersebut, seperti bermain, mendengarkan musik atau membaca buku yang memberikan stimulasi, menonton televisi atau film, dan kegiatan lain yang bersifat stimulasi 
terhadap kognitif, psikologis, dan emosional (Amalina et al., 2015).

Tidur disebabkan oleh factor fisiologis yaitu produkSi melatonim. penggunaan media dengan paparan cahaya akan menunda pelepasan melatonin sehingga menyebabkan penundaan tiduR. Penggunaa HP, menonton televisi secara otomatis sangat dekat dengan layar dan akhirnya terpapar cahaya dari benda elektronik tersebut hal inilah yang dapat menunda produksi melatonin sehingga menyebabkan gangguan tidur yaitu kesulitan memulai tidur (Zimmerman, 2008). Sleep hygiene yang kurang baik merupakan faktor risiko terjadinya gangguan tidur. Kebiasaan 30 menit sebelum tidur yang memberikan stimulasi secara kognitif, psikologis, dan emosional di antaranya adalah membaca buku, mendengarkan musik, bermain game, menonton televise, dan lain-lain. Kegiatan tersebut dapat menyebabkan seseorang menunda tidur sehingga terjadi gangguan pada pola tidur dan irama sirkardian (Amalina et al., 2015)

Perilaku sleep hygiene dalam aspek stabilitas tidur berhubungan negatif dengan gangguan tidur, hal ini berarti semakin baik perilaku sleep hygiene dalam aspek stabilitas tidur maka semakin menurun skor gangguan tidur. Stabilitas tidur dalam penelitian ini adalah waktu bangun tidur selama hari sekolah dan pada akhir pekan. Penelitian ini menunjukkan bahwa remaja yang tidak stabil dalam waktu bangun dan tidur pada hari biasa dan akhir pekan memiliki gangguan tidur. Pola bangun tidur remaja berhubungan dengan gangguan tidur pada remaja (Chung \& Cheung, 2008). Ketidakstabilan waktu tidur merupakan prediktor yang signifikan dalam gangguan tidur. Ketidak stabilan ini akan berpengaruh terhadap irama sirkardian, fisiologis tidur. Homeostatik diur dan sister sirkardian bekrja sama untuk mempromosikan pola tidur stabil dan terjaga. Waktu tidur dan bangun yang tidak teratur meningkatkan perbedaan ritme sirkardian (Irish, Kline, Gunn, Buysse, \& Martica, 2015).

\section{KESIMPULAN DAN SARAN}

Perilaku sleep hygiene remaja yang paling rendah dalam indikator kognitif artinya remaja sering melakukkan hal-hal yang membuat terjaga selama 1 jam sebelum tidur (bermain game, menonton televise), melakukan aktifitas di tempat tidur, menggunakan tempat tidur untuk hal-hal lain selain tidur misalnya menelpon, menonton televisi, bermaina game, mengerjakan PR. Semua remaja mengalami gangguan tidur, mayoritas mengalami gangguan untuk memulai dan mempertahankan tidur. Perilaku sleep hygiene signifikan berhubungan negatif dengan gangguan tidur artinya semakin baik perilaku sleep hygiene remaja maka semakin menurun gangguam tidur yang dialami. Program intervensi gangguan tidur bagi remaja berbasis sekolah dapat menjadi intervensi yang efektif untuk mempromosikan pengetahuan dan praktik tidur yang sehat. Program pendidikan kesehatan tentang sleep hygiene efektif perlu dilakukan meningkatkan kualitas tidur anak-anak usia 1018 tahun

\section{DAFTAR PUSTAKA}

Amalina, S., Sitaresmi, M. N., Gamayanti, I. L., Ilmu, B., Anak, K., Kedokteran, F., ... Gamayanti, I. L. (2015). Hubungan Penggunaan Media Elektronik dan Gangguan Tidur. Sari Pediatri, 17(4), 273-278.

Auliyanti, F., Sekartini, R., \& Mangunatmadja, I. (2015). Academic Achievement of junior high school students with sleep disorders. Paediatrica Indonesiana, 55(1), 50-57.

Calamaro, C. J., Yang, K., Ratcliffe, S., \& Chasens, E. R. (2012). Wired at a Young Age: The Effect of Caffeine and Technology on Sleep Duration and Body Mass Index in School-Aged Children. Journal of Pediatric Health Care, 26(4), 276-282.

Chung, K., \& Cheung, M. (2008). Sleep-Wake Patterns and Sleep Disturbance among Hong Kong Chinese Adolescents. SLEEP, 31(2), 185-194.

Gunarsa, S. D. (2008). Perkembangan psikologi anak dan remaja. Jakarta: Gunung Mulia.

Harmoniati, E. D., Sekartini, R., \& Gunardi, H. (2016). Intervensi Sleep Hygiene pada Anak Usia Sekolah dengan Gangguan Tidur: Sebuah Penelitian Awal. Sari Pediatri, 18(2), 93-99.

Haryono, A., Rindiarti, A., Arianti, A., Pawitri, 
A., Ushuluddin, A., Setiawati, A., ... Sekartini, R. (2009a). Prevalensi Gangguan Tidur pada Remaja Usia 1215 Tahun di Sekolah Lanjutan Tingkat Pertama, 11(3), 149-154.

Haryono, A., Rindiarti, A., Arianti, A., Pawitri, A., Ushuluddin, A., Setiawati, A., ... Sekartini, R. (2009b). The Prevalence of Sleep Disorder among Teenager 12 - 15 years old in Junior High School. Sari Pediatri, 11(3), 149-154.

Irish, L. a, Kline, C. E., Gunn, H. E., Buysse, D. J., \& Martica, H. (2015). The role of sleep hygiene in promoting public health: a review of empirical evidence. Sleep Medicine Review, 22(8), 23-36.

Kieckhefer, G. M., Ward, T. M., Tsai, S.-Y., \& Lentz, M. J. (2008). Nighttime sleep and daytime nap patterns in school age children with and without asthma. J Dev Behav Pediatr, 29(5), 338-344.

Kor, K., \& Mullan, B. A. (2011). Sleep hygiene behaviours: An application of the theory of planned behaviour and the investigation of perceived autonomy support, past behaviour and response inhibition. Psychology \& Health, 26(9), $1208-1224$.

Kozier, B. (2011). Buku Ajar Fundamental Keperawatan Kozier Vol.1 Ed.7 -. Jakarta: EGC.

Lebourgeois, M. K., Giannotti, F., Cortesi, F., Wolfson, A., \& Harsh, J. (2004). Sleep Hygiene and Sleep Quality in Italian and American Adolescents. Ann N Y Acad Sci, (1), 352-354.

Mastin, D. F., Bryson, J., \& Corwyn, R. (2006). Assessment of Sleep Hygiene Using the Sleep Hygiene Index. Journal of Behavioral Medicine, 29(3), 223-227.

Natalita, C., Sekartini, R., \& Poesponegoro, H. (2011). Skala Gangguan Tidur untuk Anak (SDSC) sebagai Instrumen Skrining Gangguan Tidur pada Anak Sekolah Lanjutan Tingkat Pertama. Sari Pediatri, 12(6), 365-372.

National Neuroscience Institute. (2014). Sleep Disorders. Retrieved April 4, 2018, from https://www.singhealth.com.sg/PatientCa re/Overseas

Noland, H., Price, J. H., Dake, J., \& Telljohann, Su. K. (2009). Adolescents , Sleep Behaviors and Perceptions of Sleep. Journal of School Health, 79(5).
Nursalam, M., Apriani, N. K., Has, E. M. M., \& Efendi, F. (2013). Sleep hygiene behavior among Balinese adolescent. Journal of Nursing Education and Practice, 4(3), 155-160.

Soetjiningsih, \& Ranuh, I. G. (2014). Tumbuh Kembang Anak (Edisi 2). Jakarta: EGC.

Storfer-Isser, A., Lebourgeois, M., Harsh, J., Tompsett, C., \& Redline, S. (2013). Psychometric Properties of the Adolescent Sleep Hygiene Scale (ASHS). J Sleep Res, 22(6).

Suen, L. K., Tam, W. W., \& Hon, K. (2010). Association of sleep hygiene - related factors and sleep quality among university students in Hong. Hong Kong Med J, 16(3), 180-185.

The National Sleep Foundation (NSF). (2015). National Sleep Foundation Recommends New Sleep Times. Retrieved March 19, 2018, from https://sleepfoundation.org

Ya'kub, Widodo, D., \& Putri, R. S. M. (2017). Gangguan Tidur Berhubungan Dengan Prestasi Belajar Pada Anak Sekolah Dasar Negeri 01 Sumber Sekar Kecamatan Dau Kabupaten Malang. Nursing News Volume, 2(2), 270-280.

Zimmerman, F. J. (2008). Children's media use and sleep problems: Issues and unanswered questions. Henry J. Kaiser Family Foundation. Retrieved from http://eric.ed.gov/ 